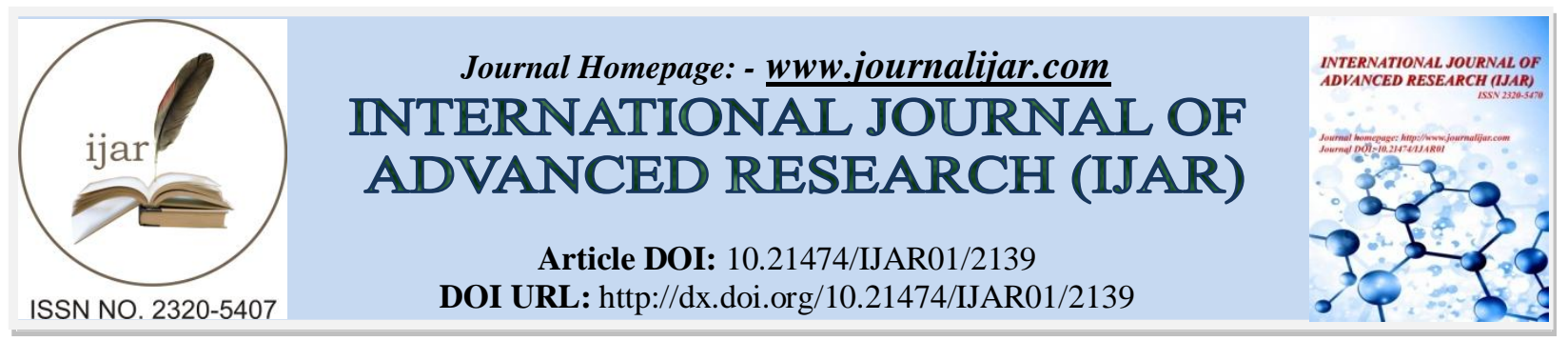

RESEARCH ARTICLE

\title{
EFFECT OF RAMADAN FASTING ON ANTHROPOMETRIC, HEMATOLOGICAL AND BIOCHEMICAL PARAMTERS OF TYPE 2 DIABETIC PATIENTS - A STUDY ON INDIAN MALE DIABETIC PATIENTS.
}

\author{
Sandhya A M ${ }^{1 *}$, Suresh Kumar $\mathbf{P}^{2}$ and Mukkadan $\mathrm{JK}^{3}$. \\ 1. Research Scholar, department of physiology, Little Flower Medical Research Centre, Angamaly, Kerala, India. \\ 2. Consultant diabetologist and Managing Director, Dr. Suresh's DiabCare India, Calicut, Kerala, India. \\ 3. Research Director, Little Flower Medical Research Centre, Angamaly, Kerala, India.
}

\section{Manuscript Info}

[.........................

Manuscript History

Received: 25 September 2016

Final Accepted: 27 October 2016

Published: November 2016

Key words:-

Ramadan fasting, Metabolic alterations, Diabetes, Intermittent Fasting

\section{Abstract}

Ramadan fasting is an excellent example of intermittent fasting. During Ramadan not only the food intake but the sleep pattern also alters. In spite of the exemption by the Islamic law many of the type 2 diabetic patients observe Ramadan fasting every year. The sudden change in the lifestyle which includes the change in eating and sleeping pattern can affect the various metabolic parameters in type 2 diabetic patients. The present study evaluated the anthropometric, hematological and biochemical parameters of type 2 diabetic males before and at the end of Ramadan fasting month. There was a significant reduction in the body weight, but blood pressure, total WBC count, total RBC count, hemoglobin, platelet count, fasting blood glucose, post prandial blood glucose, and HbA1c did not altered after Ramadan fasting. Total cholesterol remained unchanged while HDL increased at the end of Ramadan fasting. Triglycerides, LDL and VLDL decreased after Ramadan fasting. Renal function was affected by a significant increase in urea, creatinine and uric acid but was within physiological range. Total and direct bilirubin, total protein, albumin, globulin, ALT and AST did not altered during Ramadan fasting but there was a significant increase in the ALP. In conclusion observing Ramadan fasting does not harmfully affect type 2 diabetic patients.

Copy Right, IJAR, 2016,. All rights reserved.

\section{Introduction:-}

The annual observance of Ramadan fasting is considered as one of the five pillars of Islam. Ramadan fasting differs from other experimental fasting as there is involvement of psychological and sociological aspects. During Ramadan Fasting the observers must completely abstain from food, fluids, medications through any route, smoking and sexual activities. Fasting extends from pre-dawn to sunset - the length of the fasting day and month may vary by geographical location and season. There are two major meals consumed during Ramadan month, first one is the preparatory meal taken before pre-dawn and the second one is to break the fast which is taken after sunset. There is no restriction on the calorie and type of food during the non fasting hours of Ramadan [Azizi et al., 2013]. Eventhough Ramadan fasting is obligatory for all adult Muslims, the Islamic rules exempt the sick and pregnant ladies from observing fasting. Despite of this exemption majority of the type 2 diabetic patients insist to fast by 
ignoring the advice by the medical practitioners (Al-Arouj et al., 2010). One of the major and modifiable risk factor of diabetes is lifestyle especially the diet, sleep pattern and physical activities (Riserus et al., 2009). During Ramadan fasting Muslims tend to alter their dietary habits which involve changes in eating times and content of food, in addition to fluid deprivation. The altered metabolism in the type 2 diabetic patients may again affected by the altered diet and sleep pattern during Ramadan fasting (Pinar, 2002; Beshyah, 2009). It is well understood that the reduced fluid intake, the altered food timing and type may affect the metabolism especially the renal and liver functions as there are chances of dehydration and increase in the intake of fat and proteins. There are many studies on the effect of Ramadan fasting on various parameters in diabetic patients. But the results are conflicting. The results may vary according to the ethnitcity, dietary habits, and season. Most of the studies on the effect of Ramadan on diabetes were carried out in the Middle East countries. The socio economic status, culture, race and food habit of Middle East countries has a drastic difference from that of the Indian context. The present study for the first time in India assessed the anthropometric, hematological and biochemical parameters of diabetic males during Ramadan fasting without altering their food habits and medications.

\section{Materials and Methods:-}

The present study was conducted during the Ramadan month of 2014. The study subjects were selected from Dr. Suresh's Diabcare India, (A holistic centre for diabeto-cardiology and diabetic foot care) Calicut, kerala, India. Clinically proven type 2 diabetic males, above $18 \mathrm{yrs}$ of old and below $60 \mathrm{yrs}$ old, who informed their willingness to observe Ramadan fasting were included in the present study. The subjects with any auto immune diseases, cancer or any chronic or acute infections, or on prolonged medication for any other purposes and who had recently undergone radiological procedures were excluded from the current study. Those who consume alcohol and ex- and current smokers were also excluded from the current study. Sixty subjects were identified for the present study. Seven of them could not complete their fasting for the whole month. Fifty three subjects appeared for the follow up after Ramadan fasting. All the subjects were from a middle class socioeconomic back ground, who were having jobs which required physical exertion. All the subjects were informed about the present study and a written consent was obtained from each subjects.

Height and weight measurement for calculation of body mass index (BMI) were done for all the subjects. The blood pressure of the subjects was also recorded to verify hypertension. Urine and blood samples collected from subjects were considered as the materials for the present study. The urine and blood samples were collected one to three (3) days before Ramadan (R1) and on $30^{\text {th }}$ day (R2) of Ramadan. Total $7 \mathrm{ml}$ of venous blood was collected aseptically from all the subjects by venepuncture in two different sessions. The first session was after a minimum of 8 hours fasting and the second session was 2 hours after meal. Blood glucose levels, glycated hemoglobin (HbA1c), lipid profile, markers of renal function, and markers of liver function were estimated using AT-112 PLUS semiautomated clinical chemistry analyzer manufactured by Accurex Biomedical Pvt Ltd. Hematological tests were done by SYSMEX XE-2100 Haematology Automated Analyser. Quality control was done with BIO-RAD Lyphocheck Assayed Chemistry Control Level 1 and 2 of Bio-Rad Laboratories. The study was approved by the Institutional Ethics Committee.

The data analysis was performed using SPSS version 22.0. Quantitative Variables were expressed as Mean \pm SD. Comparison of quantitative variables before Ramadan fasting and after Ramadan fasting were analysed by paired $t$ test. A p-value of $<0.05$ was considered as the level of significance

\section{Results:-}

A total of 53 male diabetics were participated in the present study. The blood and urine samples were tested before (R1) and after (R2) Ramadan fasting. All the results were expressed as Mean \pm SD.

Table 1 shows the changes in anthropometric parameters of diabetic males during Ramadan fasting. There was significant reduction in the mean body weight of the subjects after Ramadan fasting when compared to before Ramadan ( $\mathrm{p}=0.001$ ). From the table 1 it is also clear that the alteration in systolic blood pressure and diastolic blood pressure after observing Ramadan fasting was not significant. Table 2 shows the changes in hematological parameter of diabetic patients after Ramadan fasting. After Ramadan mean values of total WBC count ( $\mathrm{p}=0.415)$, RBC ( $\mathrm{p}=0.328)$, hemoglobin concentration $(\mathrm{p}=0.485)$, hematocrit $(\mathrm{p}=0.453)$ and platelet count $(\mathrm{p}=0.166)$ did not show any significant change from pre-Ramadan values. 
Table 1:- Comparison of anthropometric parameters before and after ramadan fasting (mean \pm sd)

\begin{tabular}{|c|c|c|c|}
\hline Variables & R1 & R2 & P value \\
\hline BW $(\mathrm{kg})$ & $66.6 \pm 6.3$ & $65.6 \pm 5.9$ & 0.001 \\
\hline SBP $(\mathrm{mmHg})$ & $132.9 \pm 18.5$ & $132.1 \pm 15.62$ & 0.568 \\
\hline DBP $(\mathrm{mmHg})$ & $84.1 \pm 6.9$ & $84.9 \pm 6.3$ & 0.513 \\
\hline
\end{tabular}

In this $\mathrm{BW}=$ Body weight, $\mathrm{SBP}=$ Systolic blood pressure, $\mathrm{DBP}=$ Diastolic blood pressure, $\mathrm{R} 1=$ Values before Ramadan fasting, R2=Values after Ramadan fasting.

Table 2:- Comparison of hematological parameters before and after ramadan fasting (mean \pm sd)

\begin{tabular}{|c|c|c|c|}
\hline Variables & $\mathrm{R} 1$ & $\mathrm{R} 2$ & $\mathrm{P}$ value \\
\hline WBC (cells/cumm) & $7571.6 \pm 1904$ & $7272.3 \pm 1864$ & 0.415 \\
\hline RBC (million cells/cumm) & $5.02 \pm 0.67$ & $5.2 \pm 0.71$ & 0.328 \\
\hline $\mathrm{Hb}(\mathrm{gm} \%)$ & $14.1 \pm 1.1$ & $14.3 \pm 1.4$ & 0.485 \\
\hline $\mathrm{HCT}(\%)$ & $41.3 \pm 3.3$ & $41.9 \pm 4.1$ & 0.453 \\
\hline PLT (lakh cells/cumm) & $2.48 \pm 0.45$ & $2.66 \pm 1.01$ & 0.166 \\
\hline In this WBC $=$ White Blood Cells, RBC $=$ Red Blood Cells, Hb= Hemoglobin, HCT = Hematocrit, PLT= \\
Platelets, R1= Values before Ramadan fasting, R2=Values after Ramadan fasting. \\
\hline
\end{tabular}

From table 3 the glycemic status of the test subjects before and after Ramadan fasting can be understood. The mean value of fasting blood glucose (FBG) has slightly decreased from R1 (166.1 \pm 32$)$ to R2 (158.6 \pm 30.6$)$. But the decrease was not very significant $(\mathrm{p}=0.074)$. The mean values of post prandial blood glucose (PPBG) $(\mathrm{p}=0.554)$, glycated hemoglobin $(\mathrm{HbA1c})(\mathrm{p}=0.565)$ and mean blood glucose $(\mathrm{MBG})(\mathrm{p}=0.429)$ did not change significantly from R1 to R2. Table 4 shows the lipid profile of test subjects before and after Ramadan fasting. The decrease shown in mean value of total cholesterol (TC) after Ramadan fasting was not statistically significant when compared to the pre-Ramadan value $(\mathrm{p}=0.997)$. Triglyceride $(\mathrm{TG})$ has shown a significant decrease in the R2 $(151.1 \pm 40.7)$ when compared to R1 (164.4 \pm 43.0$)$. The mean high density lipoprotein (HDL) cholesterol has increased significantly in R2 (48.2 \pm 8.3$)$ when compared to R1 (44.0 \pm 4.9$)$ while a significant reduction in low density lipoprotein (LDL) cholesterol and very low density lipoprotein (VLDL) cholesterol was seen in R2 (93.1 \pm 35.9 , $30.2 \pm 8.1$ respectively) when compared toR1 (108.8 $\pm 32.7,32.8 \pm 8.6$ respectively).

Table 3:-. Comparison of blood glucose level before and after ramadan fasting (mean \pm sd)

\begin{tabular}{|c|c|c|c|}
\hline Variables & $\mathrm{R} 1$ & $\mathrm{R} 2$ & $\mathrm{P}$ value \\
\hline FBG $(\mathrm{mg} / \mathrm{dl})$ & $166.1 \pm 32$ & $158.6 \pm 30.6$ & 0.074 \\
\hline PPBG $(\mathrm{mg} / \mathrm{dl})$ & $242.2 \pm 45.6$ & $238.5 \pm 54.2$ & 0.554 \\
\hline HbA1c(gm\%) & $8.4 \pm 0.9$ & $8.3 \pm 0.5$ & 0.565 \\
\hline MBG Mean Blood Glucose(mg/dl) & $198.9 \pm 41.5$ & $193.3 \pm 30.3$ & 0.429 \\
\hline In this FBG= Fasting Blood Glucose, PPBG= Post Prandial Blood Glucose, HbA1c= Glycated hemoglobin, R1= \\
Values before Ramadan fasting, R2=Values after Ramadan fasting. \\
\hline
\end{tabular}

Table 4:- Comparison of lipid profile before and after ramadan fasting (mean $\pm \mathrm{sd}$ )

\begin{tabular}{|c|c|c|c|}
\hline Variables & $\mathrm{R} 1$ & $\mathrm{R} 2$ & $\mathrm{P}$ value \\
\hline $\mathrm{TC}(\mathrm{mg} / \mathrm{dl})$ & $179.4 \pm 29.8$ & $170.5 \pm 37.9$ & 0.997 \\
\hline TG $(\mathrm{mg} / \mathrm{dl})$ & $164.4 \pm 43.0$ & $151.1 \pm 40.7$ & 0.013 \\
\hline $\mathrm{HDL}(\mathrm{mg} / \mathrm{dl})$ & $44.0 \pm 4.9$ & $48.2 \pm 8.3$ & 0.004 \\
\hline LDL $(\mathrm{mg} / \mathrm{dl})$ & $108.8 \pm 32.7$ & $93.1 \pm 35.9$ & 0.039 \\
\hline VLDL $(\mathrm{mg} / \mathrm{dl})$ & $32.8 \pm 8.6$ & $30.2 \pm 8.1$ & 0.013 \\
\hline
\end{tabular}

In this TC $=$ Total Cholesterol, $\mathrm{TG}=$ Triglycerides, $\mathrm{HDL}=$ High density lipoprotein cholesterol, $\mathrm{LDL}=$ Low density lipoprotein cholesterol, VLDL= Very Low density lipoprotein cholesterol, R1= Values before Ramadan fasting, R2=Values after Ramadan fasting.

Table 5 describes the status of renal function of type 2 diabetics before and after Ramadan fasting. The markers of renal function like urea, creatinine and uric acid has shown a significant increase the mean values after Ramadan fasting when compared to the pre-Ramadan while microalbumin level decreased significantly after Ramadan fasting. The $\mathrm{R} 1$ values of urea, creatinine, and uric acid were $23.5 \pm 5.2,1.03 \pm 0.1,6.1 \pm 1.5$ respectively, and in $\mathrm{R} 2$ the values 
were $26.2 \pm 6.4,1.1 \pm 0.3$, and $5.5 \pm 1.0$ respectively. The microalbumin level in R1 was $20.4 \pm 8.7$ which decreased to $15.9 \pm 7.9$ in R2. From Table 6 we can understand the variations in the markers of liver function during Ramadan fasting. The mean values of bilirubin levels - total and direct, did not change from R1 to R2 significantly. Total protein (TP) as well as albumin and globulin values also did not show much difference from R1 to R2. The alanine amino transferase (ALT) and aspartate amino transferase (AST) remained unchanged in R2 when compared with

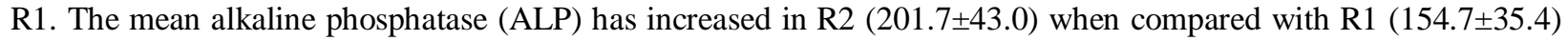
and the change was significant $(\mathrm{p}=.000)$.

Table 5:- Comparison of markers of renal function before and after ramadan fasting (mean \pm sd)

\begin{tabular}{|c|c|c|c|}
\hline Variables & $\mathrm{R} 1$ & $\mathrm{R} 2$ & $\mathrm{P}$ value \\
\hline Urea $(\mathrm{mg} / \mathrm{dl})$ & $23.5 \pm 5.2$ & $26.2 \pm 6.4$ & 0.011 \\
\hline Creatinine $(\mathrm{mg} / \mathrm{dl})$ & $1.03 \pm 0.1$ & $1.1 \pm 0.3$ & 0.024 \\
\hline Uric acid $(\mathrm{mg} / \mathrm{dl})$ & $6.1 \pm 1.5$ & $5.5 \pm 1.0$ & 0.027 \\
\hline Microalbumin $(\mathrm{mg})$ & $20.4 \pm 8.7$ & $15.9 \pm 7.9$ & 0.001 \\
\hline \multicolumn{2}{|l|}{ In this R1= Values before Ramadan fasting, R2=Values after Ramadan fasting. } \\
\hline
\end{tabular}

Table 6:- Comparison of markers of liver function before and after ramadan fasting (mean \pm sd)

\begin{tabular}{|c|c|c|c|}
\hline & $\mathrm{R} 1$ & $\mathrm{R} 2$ & $\mathrm{P}$ value \\
\hline Bil D (mg/dl) & $0.3 \pm 0.2$ & $0.3 \pm 0.1$ & .270 \\
\hline Bil T (mg/dl) & $0.9 \pm 0.2$ & $1.0 \pm 0.3$ & .212 \\
\hline $\mathrm{TP}(\mathrm{mg} / \mathrm{dl})$ & $6.4 \pm 0.6$ & $6.5 \pm 0.5$ & .323 \\
\hline ALB (mg/dl) & $3.6 \pm 0.2$ & $3.5 \pm 0.3$ & .126 \\
\hline GLB (mg/dl) & $2.8 \pm 0.4$ & $2.9 \pm 0.2$ & .234 \\
\hline ALT (U/L) & $27.4 \pm 9.0$ & $27.9 \pm 8.2$ & .769 \\
\hline AST (U/L) & $27.2 \pm 9.1$ & $27.7 \pm 11.7$ & .817 \\
\hline ALP (U/L) & $154.7 \pm 35.4$ & $201.7 \pm 43.0$ & .000 \\
\hline \multicolumn{4}{|c|}{$\begin{array}{l}\text { In this Bil } \mathrm{D}=\text { Direct bilirubin, Bil } \mathrm{T}=\text { Total bilirubin, } \mathrm{TP}=\text { Total protein, } \mathrm{ALB}=\text { Albumin, } \mathrm{GLB}=\text { Globulin, } \\
\qquad \begin{array}{l}\mathrm{ALT}=\text { Alanine amino transferase, } \mathrm{AST}=\text { Aspartate amino transferase, } \\
\mathrm{ALP}=\text { alkaline } \mathrm{phosph} \text { atase, } \\
\mathrm{R} 1=\text { values before Ramadan fasting, } \mathrm{R} 2=\text { Values after Ramadan fasting. }\end{array}\end{array}$} \\
\hline
\end{tabular}

\section{Discussion:-}

The present study evaluated the anthropometric, hematological and biochemical parameters of 53 type 2 diabetic male patients who observed Ramadan fasting. The body weight was significantly decreased after observing Ramadan fasting. This is in line with Khaled et al., 2006 and Mafauzy et al., 1990 who observed decrease in body weight after fasting in Algerian and malaysian diabetic population respectively. Increase in body weight (kamar $e t$ al., 2015) and no change in body weight is also reported (AlAlwan and Al Banyan, 2010; Bouzid et al., 2016). Usually during Ramadan, the frequency of food intake decreases and along with this, the fluid restriction which leads to dehydration might have caused weight reduction. The weight reduction did not lead to significant alteration in the arterial blood pressure in the present study. Eventhough there was slight decrease in the systolic blood pressure, it was not statistically significant. Norouzy et al., 2012 also reported an unaltered blood pressure in diabetic patients after Ramadan fasting. All the subjects in the present study were normotensive. The increase in the dietry fibre and rehydration in the evening could have a role in maintain the blood pressure in the normal level.

The current study indicates that there was no development of anemia during Ramadan fasting on the light of results of the hematological parameters. The hematological parameters such as total WBC count, total RBC count, hemoglobin, hematocrit and platelet did not show any significant difference after observing Ramadan fasting. Norouzy et al., 2012 observed a consistent WBC count and HCT, while RBC, hemoglobin and platelet increased. Decrease in RBC and platelet was observed by M'Guill et al., 2007. Eventhough fluid and food intake is restricted during fasting hours; the food items used in the non fasting hours of Ramadan are usually rich in iron and fibers like dates, vegetable salads and fruit juices. The redistribution of micronutrients might have helped to maintain the normal distribution of plasma and the blood cells.

The glycemic status was well maintained by the diabetic people during Ramadan fasting as evidenced by the results of the present study. There was a non-sigificant decrease in the fasting blood sugar while the parameters like post prandial blood sugar, mean blood glucose and HbAlc did not altered. Khatib and shafagoj, 2004 also found that 
blood sugar level and HbA1c did not change in normal weight people. Weight reduction has shown to improve the insulin resistance and improve the glycemia in diabetics (Ludwig, 2002).

In the present study Ramadan fasting has shown a favorable effect on lipid profile. The triglyceides decreased and the total cholesterol remained unchanged while HDL has increased and LDL and VLDL decreased. Uysal et al., 1998 found an increased HDL, while LDL, TG and TC did not alter. Saada et al., 2010 has found an increase in HDL, and decreases in TC, TG LDL and VLDL. The disparity in the results may be due to the difference in the type of food and the physical activities by the subjects. In the present study the subjects were having physical exertion as part of their job during the Ramadan fasting period. These physical activities require more energy for which the body might have used fat as a substrate. This might have led to decrease in LDL and TG.

The increase in renal function markers, the urea, creatinine and uric acid seen in the present study is possibly due to a hypohyration resulted from the reduced fluid intake during day time which is reinforced by the osmotic dieresis of diabetic patients. Similar results have been observed by Azwany et al., 2004. But the increase seen was under physiological limit and the microalbuminuria was improved after fasting which indicate that glomerular membrane health was not harmfully affected by Ramadan fasting. Reducing body weight with normal blood pressure and well controlled blood glucose in diabetic patients may reduce the microalbumin level in urine (koroshi et al., 2007). No previous studies have been reported on the microalbumin level of diabetic after Ramadan fasting.

Liver function in type 2 diabetic also was not affected adversely by Ramadan fasting except there was a significant increase in the alkaline phosphatase level. Birubin levels, total protein, albumin, globulin, ALT and AST did not change after Ramadan fasting. In a previous study by M'guil et al., 2008 has noticed decrease in total protein, ALT, AST, and increase in bilirubin but ALP was not altered. This is in contrast with the present result. ALP is not a specific marker of liver function. Any biliary duct disease or malnutrition can alter the ALP levels. More studies are required for the exact reason of increase in ALP after fasting.

\section{Conclusion:-}

The present study has observed that Ramadan fasting has a beneficiary effect on body weight, lipid profile and microalbuminuria. Ramadan fasting does not altered the glycemic status and hematological parameters. Ramadan fasting has adversely affected the renal function but not clinically relevant as the values were within physiological limit. The liver function was also not adversely affected by Ramadan fasting. These results point that Ramadan fasting is safe for type 2 diabetics.

\section{Reference:-}

1. AlAlwan, I. and Al Banyan, A. (2010): effects of Ramadan fasting on children with type 1 diabetes. International Journal of Diabetes Mellitus, 2(2), pp.127-129.

2. Al-Arouj, M., Assaad-Khalil, S., Buse, J., Fahdil, I., Fahmy, M., Hafez, S., Hassanein, M., Ibrahim, M.A., Kendall, D., Kishawi, S. and Al-Madani, A. (2010): Recommendations for management of diabetes during Ramadan update 2010. Diabetes care, 33(8), pp.1895-1902.

3. Azizi, F. (2013): Islamic fasting and diabetes. Journal of Fasting and Health, 1(1), pp.1-5.

4. Azwany, N., Aziz, A.I. and Mohammad, W. (2004): The Impact of ramadan fasting on hydration status of type 2 diabetics in kubang kerian, kelantan. Jurnal Kesihatan Masyarakat, 10(S), pp.31-34.

5. Beshyah, S.A. (2009): Fasting during the month of Ramadan for people with diabetes: medicine and Fiqh united at last. Ibnosina Journal of Medicine and Biomedical Sciences, 1(2), pp.58-60.

6. Bouzid, K., Molahedh, Y., Hmaidi, W., Mchirgui, N., Bartkiz, A., Talbi, E., Abdallah, N.B., Bahlous, A. and Abdelmoula, J. (2016): Effects of Ramadan fasting on clinical and biochemical parameters for type 2 diabetics. Atherosclerosis, 252, p.e93.

7. Kamar, M.E., Orabi, A.A., Salem, I.M. and EL-Shabrawy, A.M. (2015): Effect of Ramadan Fasting On Diabetic Micro-Vascular Complication. Zagazig University Medical Journal, 20(2).

8. Khaled, B.M., Bendahmane, M. and Belbraouet, S. (2006): Ramadan fasting induces modifications of certain serum components in obese women with type 2 diabetes. Saudi medical journal, 27(1), pp.23-26.

9. Khatib, F.A. and Shafagoj, Y.A. (2004): Metabolic alterations as a result of Ramadan fasting in non-insulindependent diabetes mellitus patients in relation to food intake. Saudi medical journal, 25(12), pp.1858-1863.

10. Koroshi, A. (2007): Microalbuminuria, is it so important. Hippokratia, 11(3), pp.105-107. 
11. Ludwig, D.S. (2002): The glycemic index: physiological mechanisms relating to obesity, diabetes, and cardiovascular disease. Jama, 287(18), pp.2414-2423.

12. Mafauzy, M., Mohammed, W.B., Anum, M.Y., Zulkifli, A. and Ruhani, A.H. (1990): A study of the fasting diabetic patients during the month of Ramadan. Med J Malaysia, 45(1), pp.14-7.

13. M'guil, M., Ragala, M.A., El Guessabi, L., Fellat, S., Chraibi, A., Chebraoui, L., Israili, Z.H. and Lyoussi, B. (2008): Is Ramadan fasting safe in type 2 diabetic patients in view of the lack of significant effect of fasting on clinical and biochemical parameters, blood pressure, and glycemic control?. Clinical and experimental hypertension, 30(5), pp.339-357.

14. Norouzy, A., Mohajeri, S.M.R., Shakeri, S., Yari, F., Sabery, M., Philippou, E., Varasteh, A.R. and Nematy, M. (2012): Effect of Ramadan fasting on glycemic control in patients with Type 2 diabetes. Journal of endocrinological investigation, 35(8), p.766.

15. Pinar, R. (2002): Management of people with diabetes during Ramadan. British journal of nursing, 11(20), pp.1300-1303.

16. Risérus, U., Willett, W.C. and Hu, F.B. (2009): Dietary fats and prevention of type 2 diabetes. Progress in lipid research, 48(1), pp.44-51.

17. Saada, D.A., Selselet, G., Belkacemi, L., Chabane, O.A., Italhi, M., Bekada, A.A.M. and Kati, D. (2010): Effect of Ramadan fasting on glucose, glycosylated haemoglobin, insulin, lipids and proteinous concentrations in women with non-insulin dependent diabetes mellitus. African Journal of Biotechnology, 9(1).

18. Uysal, A.R., Erdogan, M.F., Sahin, G., Kamel, N. and Erdogan, G. (1998): Clinical and metabolic effects of fasting in 41 type 2 diabetic patients during Ramadan. Diabetes care, 21(11), p.2033. 